\title{
Shifting from STEM to STEAM - Reflecting on Academic Identity and Scholarship
}

\author{
Rosanne Quinnell ${ }^{\mathrm{a}}$ \\ Corresponding author: Rosanne Quinnell (rosanne.quinnell@sydney.edu.au) \\ a School of Life and Environmental Sciences, Faculty of Science, The University of Sydney, Sydney NSW 2006, Australia
}

Keywords: science, technology, arts, engineering and mathematics; academic identity

\begin{abstract}
This paper offers some backgrounding on the sometimes vexed area of 'academic identities' through descriptions and reflections of select moments in my career where my scholarly work was informed by my home discipline of Biology and extended into other discipline spaces, specifically the Arts. I offer examples of my work where the "A" in STEAM is evident including examples of poetry and visual art projects that have allowed for the communication of ideas without the constraints of scientific prose. I reflect on the importance (to me) of working across disciplines as fields of practice and of connecting with others like me within science (including students), and across and outside of science and so offering validation. These Science-Art moments have given me permission to be myself, to exhale.
\end{abstract}

\section{Introduction}

I have trod an interesting path during my academic career. All academic pathways are unique, with some pathways being hindered or facilitated by decisions that are made at all levels of influence (e.g. federal, institutional, faculty, department, discipline, research group). Over the past 25 years the impacts of these decisions have opened up new spaces and manifested career opportunities for me. Whilst at other times I have struggled to find the space to continue to do the work where my curiosity is piqued, here I exercise my creativity and here I feel happy. What seems to characterise these spaces where I create joy in my work is that they fall between and draw together disciplines. Given the in-between nature of my creativity, it will come as no surprise that during my career I have grappled with my academic identity. Formally I am an academic sitting in the rigid confines of science - however, many times I have opted not to swim between the flags of science (and biology in particular) arguing (very quietly to myself) that the positioning of the flags and ruling that I swim only between them does not allow me to do my best work.

Now that I am in the last phase of my career and I have well and truly hit my stride, I feel the need to focus my work more intently at the edges where boundaries can be challenged, and the nature of thresholds characterised. I now recognise that the key 'a-ha' moments of my career have all occurred in the spaces at the edges of (life) science. Exploring where science interfaces with non-science disciplines has revealed a continuum of liminality - the liminality space being where my creativity and curiosity seem to be at their highest. Exploring the boundaries of science has enable me to gain an understanding of the limitations within scientific thinking. I think it is more useful to ask how practices of, say, a scientist, an historian and a composer are similar, rather than asking 'how are they different?' 
I offer a collection of my experiences collaborating at the very edges of science, the places and spaces where there is a blurring and blending of sciences and arts. These are the places where I have sought to dip my toe outside of science and where I have found personal and professional rewards for loosening the ties of the science discipline thinking and practice corset. Spaces that are changeable, where I don't have the answers, I have few predictions, and where my thinking can stretch further. It is here, when I am grappling with uncertainty, that I find joy.

\title{
Disciplinarity and identity
}

The research of Biglan (1973) and Becher and Trowler (2001) has been extremely useful for helping me to critique disciplinary ways of doing, being and knowing in my working environment. So too is the work of Perkins, Jay and Tishman (1993), who describe these somewhat tacit behaviours as 'discipline sensitivities'. As a biology educator, my job is to introduce students (who present as discipline novices) into the ways of thinking like a (seasoned) biologist and to develop our discipline 'sensitivities'. In my teaching, explicitly highlighting the fundamentals of what is required to make sense of biology includes offering the accepted conventions of recording data. This teaching practice clearly goes beyond offering 'content' and is, in effect, revealing the hidden curriculum. The 'hidden curriculum' was originally used to describe how students needed to be familiar with how the learning process occurs and how to behave within it (Jackson, 1990); it has evolved to refer to the influences that transform a student to possess the somewhat intuitive thinking of a given discipline e.g. thinking like a doctor (Ozolins, Hall, \& Peterson, 2008). It is within the discipline that decisions about both teaching and research are discussed and organised (Quinnell, Russell, Thompson, Marshall, \& Cowley, 2010) and that decisions are shaped by the consensus disciplinary values (Becher \& Trowler, 2001) where each disciplinary teaching and learning regime has different concepts of identity, tacit assumptions, codes of significance, rules and recurrent practices (Trowler \& Cooper, 2002). Stepping outside of ones' home discipline comes with challenges, including learning the language of a new discipline; in, for example, education research there is a wealth of frameworks and taxonomies. By comparison with my home discipline, biology has only one taxonomic frame (aligned with the evolutionary process).

Of late we have been hearing a lot about STEM(M) science, technology, engineering, mathematics (and medicine, I will keep with STEM for this paper). The Education Council of Australia (2015) argues for a stronger focus on STEM education but does not explicitly advocate for an expansion of STEM teaching and learning remit to create transdisciplinary opportunities across STEM disciplines, with the exception of mathematics where integration with other disciplines is explicitly advocated. When 'arts' disciplines are added STEM becomes STEAM, the remit shift to being all about transdisciplinarity. Writing in support of the inclusion of arts in STEM, Taylor (2018) asserts that "the arts enable us to discover our humanity", which is critical for engaging in social, ethical and cultural dimensions of scientific endeavours. Operating with legitimacy in the transdisciplinary STEAM raises the issue of where do we find our own academic authenticity in the transdisciplinary environment?

\author{
I find myself here \\ tidal rhythm of Earth and Moon \\ high and low \\ ebb and flow \\ the shore \\ both land and sea
}




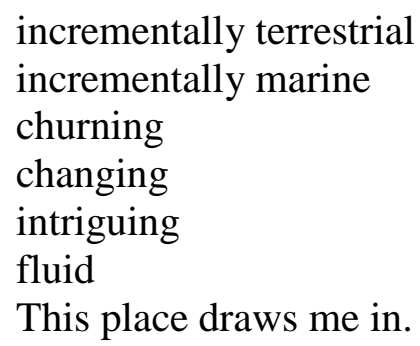

Looking back, I have tended to dwell in those places, spaces where differences are reconciled, where symbiotic partners both gain advantage. I offer my reflections of some of the key moments in my career where I have traversed my home discipline and another in my teaching, and in my scholarship, as I have moved from STEM to STEAM.

My first step was one I have in common with many, which has extended my scholarly remit to include education research (specifically the scholarship of learning and teaching, SoTL). I have a strong sense that my legitimacy as a scientist was called into question when I began to occupy interscholarly spaces and conduct research in science education. In recent times I have travelled even further from my home discipline to explore the limits of my own scholarship.

I have mapped my transdisciplinary wandering onto a discipline matrix similar to the one offered by Biglan (1973) where the disciplines of STEAM occupy all four quadrants (generalists - professionals, hard - soft) (Figure 1). Biglan's matrix has been useful in that it has allowed me to think about commonalities between disciplinary approaches and where disciplinary practices differ. It is not only about differences in 'hard' and 'soft' disciplines. The vertical axis is 'pure' and 'applied' and again there are different practices and perspectives when accreditation requirements are in the mix and when the intent is to have clear application for research at the outset. Research in science and researching science education do not colocate on Biglan's matrix, mapping to (hard-pure discipline and soft-applied discipline, respectively). I have used Biglan's matrix a few times in my research. Most recently Biglan's matrix was used to map the degrees of students in first year biology to get a sense of cohort discipline diversity (Quinnell, May, Davila, \& Peat, 2018); we argued that improvements in engagement with learning of our students in biology would be supported by systems that allow the students to assess for themselves how their approaches to study (surface or deep, Biggs, 1987) and conceptions of biology (fragmented or cohesive, Quinnell, May, Peat, \& Taylor, 2005; after Crawford, Gordon, Nicholas, \& Prosser, 1998), develop over the course of their studies. There is a clear parallel with advocating that students engage with factors that inform learning and the mapping exercise to explore my own scholarship that I present in this paper.

In part, the different research practices and perspectives explain why many researchers in science do not, in my experience, perceive 'science education research' to have the legitimacy as 'science research'. I have chosen to park the dilemma of whether or not my education research is in fact research using the term 'scholarship' to cover my creative endeavours in science, education, and academic professional development. Debate about the interchangeability of the terms 'research' and 'scholarship' will continue, but my preference for using the term 'scholarship' infers that the boundaries between discipline quadrants is porous. In short, I find liminality and fluidity of thought in transdisciplinary spaces where I can keep a foot in my home discipline of Biology, which is located within 'hard' discipline of science and step into the 'soft' disciplines. The stretch may not be as much as you think. This quote from Castro and Marcos (2011) speaks to rationality being common across science and art, and they do not shy away from rationality and creativity as they are linked: 
...there is a common human rationality in both scientific and artistic creative practices. That rationality is present not only in the justification of scientific theories, but also in their creation. It is not a rigid rationality... but a flexible one. In the same way, artistic creation is not born out of an irrational source; rather, this same prudential rationality is at work in it. This common human rationality, then, establishes a bridge between artistic and scientific creativity (p.11).

I am cognizant that the measured, performance-driven academy (e.g. Hazelkorn, Coates, \& McCormick, 2018) requires me to justify time spent on scholarly efforts through outputs that can be included in my institution's research dossier. Departing from the rigidity of journal publications has come with a level of risk to my career. Regardless I have pressed on. I offer examples below from my scholarly portfolio. These examples are ones that most readily come to mind when I think about the porosity (or lack thereof in the case of how students in biology perceive mathematics) between academic disciplines.

\title{
Exploring discipline pedagogy in the context of SoTL
}

I was afforded an opportunity to explore learning and teaching practices across Science when I was Fellow for Science at UNSW. The Learning and Teaching Fellows Program brought together discipline scholars from across the University (one from each Faculty or equivalent i.e. across STEAM) who were appointed to focus on mechanisms to improve the 'student experience' (Brawley, et al., 2009). The program was funded from UNSW's Learning and Teaching Performance Fund allocation from the Federal Government. From our respective disciplinary positions, we, the fellows, explored the importance of discipline perspectives and narratives in the SoTL discourse and in authentic academic development. I was better able to situate my science education research having connected with scholars from other disciplines. This experience enabled me to delimit the edges of my science practices in research and in teaching (Quinnell et al., 2010) and to start to characterise the discipline sensitivities of biology. This experience was critical for me as a biologist and a scientist, but more important to develop my academic identity, explore my values, and to develop greater depth in my scholarship.

The disciplinary map I offer here (see below) has exposed the transdisciplinary nature and scholarly merit of my work and affords legitimacy to how I have positioned myself in the academy.

\section{Working across a pedagogical divide: Science and mathematics}

\author{
Biomaths \\ Eyes averted \\ They hide. \\ Stopped by \\ learnt fear. \\ Coaxing \\ Enticing \\ with biological patterns \\ piquing \\ curiosity. \\ And love of number.
}




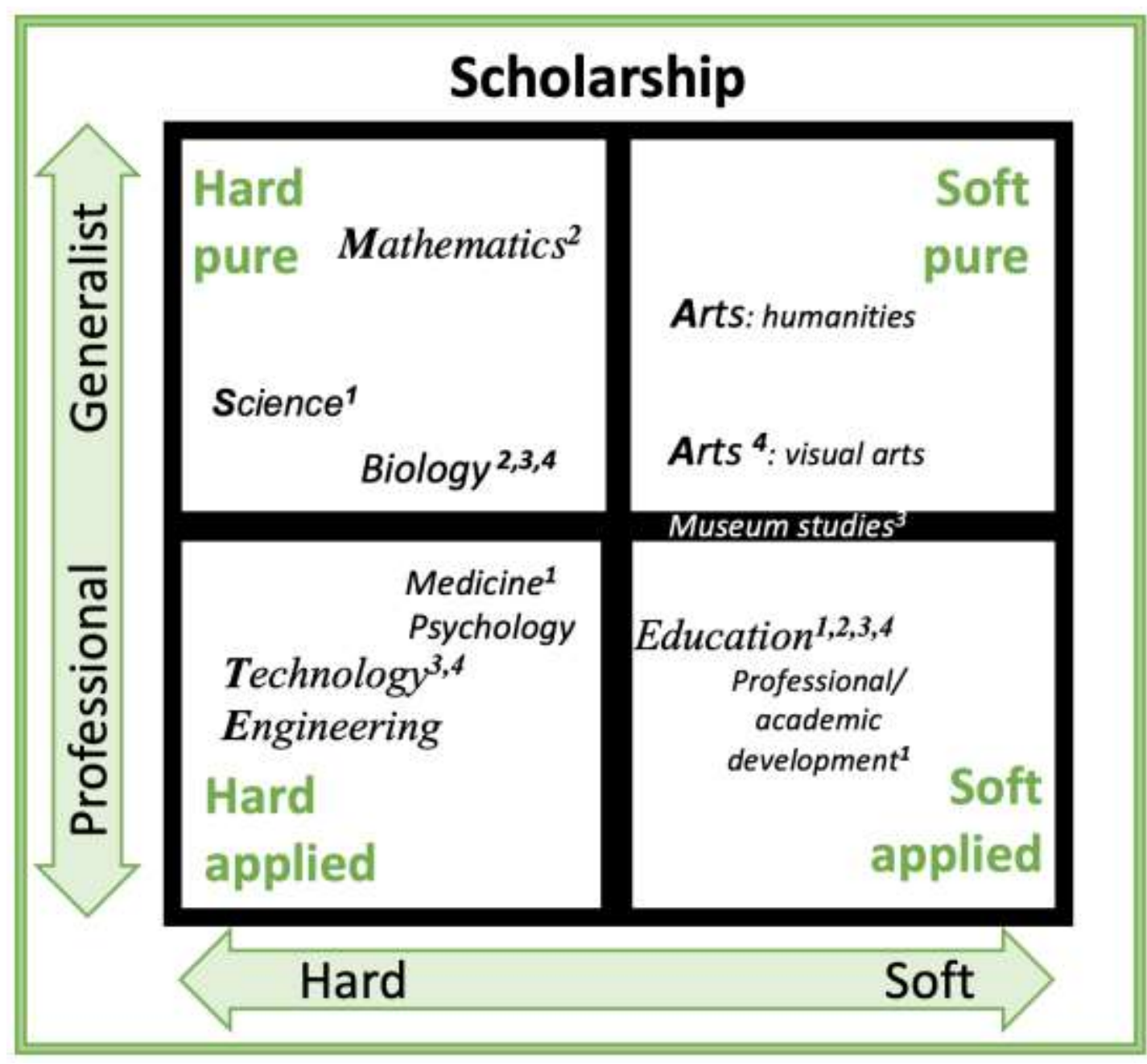

1. Map of scholarly disciplines of Science, Technology, Engineering, Arts and Mathematics (STEAM) imposed onto Biglan's (1973) discipline matrix.

Transdisciplinary projects that map to ever-expanding boundaries from STEM to STEAM.: 1. Scholarship of learning and teaching, including discipline narratives, 2. Biology students' perceptions of Mathematics 3. Museum studies in Life Sciences, 4. Exhibition spaces for botanical images.

Despite biology and mathematics occupying the same quadrant on Biglan's matrix, the distance between mathematics and biology from the perspectives of our students is seemingly enormous. The same is true for many medical students who share a less than ideal relationship with mathematics (e.g. LeBard, Thompson, \& Quinnell, 2014; Quinnell, Thompson, \& LeBard, 2013). In biology, we assume that numeracy skills acquired in school will be effortlessly transferred when students are required to manipulate their quantitative data as part of reporting experimental data. My colleagues and I have been unpicking the uncomfortable relationship many biology students have with mathematics. We have focused our work around recognising where and when students disengage from learning - where there is a transfer maths anxiety (Quinnell \& Thompson, 2010) rather than their numeracy skills. The requirement to be impartial in science is challenged when learning biology elicits palpable emotions from students, particularly when the topic is mathematics. 


\title{
Museum studies and our institution's educational legacy circa 1900
}

\author{
Haswell collection digitisation \\ Shelves of floating specimens \\ A.A. Lawson \\ No legs, 4 legs, 6 legs, 8. \\ Caught \\ The room bright \\ with botanical wonders. \\ The storyteller \\ Kept \\ illuminating their minds. \\ Coded \\ Curated \\ Alive again \\ Online
}

Science educators are science communicators. Over the past few years I have been connected with the Sydney University Museums on a shared interest in biology educators who have left an educational legacy for our current students. Two such educators are Abercrombie Anstruther Lawson and William Aitchison Haswell.

Lawson (1870 - 1927) was the foundation Professor of Botany at The University of Sydney who had a collection of lantern slides which he had hand-coloured. These slides (the precursors to Powerpoint ${ }^{\circledR}$ ) were extremely popular in his public lectures and, in addition to taking teaching and learning of botany to the general public, Lawson was a strong advocate of learning in the field and in the laboratory.

William Aitchison Haswell (1854 - 1925) was a zoologist who established a comprehensive collection of zoological specimens for teaching. It has been a joy to re-illuminate the value of both Lawson's (Rayner \& Quinnell, 2016) and Haswell's contributions to teaching and learning biology at the University of Sydney. The Haswell collection is registered with the Atlas of Living Australia (Sowden 2018), and, like the eBOT botanical image repository (Henwood et al., 2010), once completed, the Haswell collection will be offered as a digital collection and in due course will be registered with Australian National Data Service.

\section{Botanical images as public exhibitions}

\author{
\#iamabotanist \\ Thank you for my oxygen and sequestering my waste \\ Thank you for the shade and \\ Thank you for your taste \\ Thank you for housing all of the critters, \\ The birds, the bees, koalas and invertebrates in your litter. \\ Thank you for your flowers signalling when seasons change \\ Marking times joy and grief, \\ Assuaging my pain. \\ Medicine and fibres \\ So many gifts for free \\ There is little wonder \\ My favourite colour is green.
}

I love plants and derive enormous joy from working with botanical images. A large part of developing botanical literacy is spending time examining anatomical and morphological 
patterns of plant organs and tissues in diverse species and at a range of scales (macroscopic to microscopic. I have devoted my time to developing learning support for students as they grapple with the concepts and the language of biology generally, and of botany in particular.

New and emerging technologies have informed the educational design of these learning resources, which by and large have been image-rich. Most recently I have co-developed mobile apps with students and so the creation of supplementary, flexible learning spaces to sit alongside formal classroom resources. My colleagues (including undergraduates) and I have written about the mobile app 'CampusFlora' previously (e.g. Pettit, Pye, Wang, \& Quinnell 2014; Cheung, Wardle, \& Quinnell, 2015). Suffice to say here, that the scholarship and research that framed the iOS CampusFlora (i.e. 'botanical literacy') led to its being registered as a digital creative work as the app is akin to an online exhibition of botanical images (Quinnell, Pettit, Pye, Pursey, \& Wang, 2014). This non-traditional scholarly output sits alongside the more traditional peer-reviewed outputs from this project, the tangible rewards of undertaking a relatively unconventional project, which has fostered an ongoing effective student- and staff research partnership.
Studies in $g$
One force
Life obedient
We see balance
We hear harmony
We perceive beauty

At the microscopic level, images - micrographs - of plants are compelling. I have been teaching plant anatomy for 20 years and one of my favourite times is in the first plant anatomy practical class when students are required to prepare their own plant sections for examination of cellular patterns and structures under the microscope. In these plant anatomy classes, the movement of students through a critical learning threshold of physically preparing their own material for examination with a microscope is met with 'wow!'s from the students when they visually experience the wonders of microscopy. The visual patterns of botany audibly draw students across a learning threshold (see Meyer \& Land, 2003 for discourse on disciplinary Threshold Concepts).

These patterns from the botanical world are not lost on those outside of science. In 2016, I was invited to contribute images to a VIVID exhibition (Crossley et al., 2016). My involvement in VIVID was an important moment and participation in VIVID expanded my view of scholarship. I enjoy offering images of plants, including micrographs of students (with permission) to the University community on the organisation's social networking system. The idea of offering a botanical exhibition became real at the end of last year. My former honours student and I mounted a charity exhibition of ten botanical micrographs entitled HARVEST with proceeds going to the family of a Cambodian farmer who had supported my student's fieldwork (Howell \& Quinnell, 2018).

\section{Concluding remarks}

During my career I have run to catch up to those who were selected for success early on their careers. I have been buffeted by the winds of organisation change and have been required to jump (a lot). I have tripped and I have fallen - sometimes wondering how I could ever get up. I've cried. And cried. At the lowest points I could still find the joy in my scholarship - a sheltered haven. Right now, I stop. Gathering my thoughts. The mapping process offered here 
may be of use to others whose work sits across disciplinary spaces. For me, mapping the spaces in-between where my scholarship has taken me being a pre-cursor to planning where I will go next in my career.

\section{Acknowledgements}

I am grateful to Pauline Ross and Philip Poronnick for affording me opportunities to share my project work that sits across (and between) disciplines with my colleague biology educators (2014 and 2016 (Vision and Innovation in Biology Education group, 2014; Biology Educators Australia Network - BEAN, 2016). Elements of this paper were offered at the 2016 BEAN conference in my presentation entitled "Working in the Spaces In-Between". I offer my thanks to Melinda Lewis their feedback and support while writing this paper.

\section{References}

Becher, T., \& Trowler, P.R. (2001). Academic Tribes and Territories: Intellectual enquiry and the culture of disciplines (2nd ed.). Buckingham UK: The Society for Research into Higher Education and Open University Press.

Biggs, J.B. (1987). The Study Process Questionnaire (SPQ) Users' Manual. Hawthorn, Victoria.

Biglan, A. (1973). Relationships between subject matter characteristics and the structure and output of university departments. Journal of Applied Psychology, 57(3), 204-213.

Brawley, S., Clark, S., Cockburn, T., Cowley, J., Eijkman, H., Marshall, N., Quinnell, R., Russell, C., Thompson, R., \& Zamberlan, L. (2009). Learning and Teaching Fellows in the Australian Higher Education Sector. HERDSA Newsletter December 2009., 12 - 14.

Castro, S. J. \& Marcos, A. (2011). The paths of creation; creativity in science and art. P. Lang, Bern ; New York

Cheung, C., Wardle, G., \& Quinnell, R. (2015). Campus Flora: a digital education and engagement tool to turn whole campuses into interactive learning spaces. Bulletin of the Ecological Society of Australia, 3(45), 1719.

Crawford, K., Gordon, S., Nicholas, J., \& Prosser, M. (1998). Qualitatively different experiences of learning mathematics at university. Learning and Instruction, 8(5), 455-468.

Crossley, J., Poronnick, P., Quinnell, R, Thoms, D., Oakford, J., \& Ollerenshaw, S. (2016). True Life. In: Vivid. Light, Music, Ideas. 27 May - 18 Jun 2016 Sydney, Australia.

Education Council. (2015). National Science, Technology, Engineering and Mathematics (STEM) School Education Strategy Retrieved 1 April, 2019:

http://www.educationcouncil.edu.au/site/DefaultSite/filesystem/documents/National\%20STEM\%20School\% 20Education\%20Strategy.pdf

Hazelkorn, E., Coates, H., \& McCormick, A. C. (2018). Research Handbook on Quality, Performance and Accountability in Higher Education. In Quality, performance and accountability: emergent challenges in the global era.

Henwood, M., Quinnell, R., Brownlee, R, Hanfling, S., Regan, C., \& Price, J. (2010). eBot plant sciences collection. The University of Sydney. Research Data Australia, Australian National Data Service. Retrieved 1 April, 2019: https://researchdata.ands.org.au/ebot-plant-sciences-collection/11131

Howell, D., \& Quinnell, R. (2018). HARVEST: celebrating generosity. Photographic exhibition and fundraiser. 16th Dec, 2018.

Jackson P (1990) Life in Classrooms. pp. 33-35. New York: Teachers' College Press

LeBard, R., Thompson, R., \& Quinnell, R. (2014). Quantitative Skills and Complexity: How can we Combat these Challenges and Equip Undergraduate Students to Think and Practice as Biologists? International Journal of Innovation in Science and Mathematics Education. Special Issue: Biology Education Futures., 2(3), 1 - 14.

Meyer, J., \& Land, R. (2003). Threshold Concepts and Troublesome Knowledge- linkages to ways of thinking and practising. In Rust C (Ed.), Improving Student Learning - Ten Years On. (pp. 412-424). Oxford: Oxford Centre for Staff and Learning Development.

Ozolins, I., Hall, H., \& Peterson, R. (2008). The student voice: recognising the hidden and informal curriculum in medicine. Medical Teacher, 30(6), 606-611. doi:10.1080/01421590801949933

Pettit, L., Pye, M., Wang, X., \& Quinnell, R. (2014). Designing a bespoke App to address botanical literacy in the undergraduate science curriculum and beyond. In B. Hegarty, J. McDonald, and S.-K. Loke (Eds.), ascilite Rhetoric and Reality: Critical perspectives on educational technology., pp. 614-619. Dunedin.

Perkins D.N., Jay. E., \& Tishman S. (1993) Beyond abilities: A dispositional theory of thinking. Merrill Palmer Quart. 39:1-21. 
Quinnell, R., May, E., Peat, M., \& Taylor, C. E. (2005). Creating a reliable instrument to assess students' conceptions of studying biology at tertiary level. Proceedings of the Uniserve Science Conference: Blended Learning in Science Teaching and Learning. Retrieved 1 April, 2019, from https://openjournals.library.sydney.edu.au/index.php/IISME/article/view/6460/7107

Quinnell, R., Pettit, L., Pye, M., Pursey, A., \& Wang, X. (Producer). (2014). Campus Flora iOS app. Digital Creative Work. [iOS app] Retrieved 1 April, 2019: https://itunes.apple.com/au/app/campusflora/id918408102

Quinnell, R., Russell, C., Thompson, R., Marshall, N., \& Cowley, J. (2010). Evidence-based narratives to reconcile teaching practices in academic disciplines with the scholarship of teaching and learning. Journal of the Scholarship of Teaching and Learning, 10(3), 20 - 30.

Quinnell, R. (2016). Working in the spaces in between. Paper presented at the Biology Educator Australia Network, ANU.

Quinnell, R., May, E., Davila, Y., \& Peat, M. (2018). Profiling our Students' Learning Orchestrations to Evaluate the Biology Curriculum. International Journal of Innovation in Science and Mathematics Education, 26(3), 21-39.

Quinnell, R., \& Thompson R. (2010) Conceptual Intersections: Re-viewing academic numeracy in the tertiary education sector as a threshold concept. In: Meyer J H F, Land R, Baillie C, editors. Threshold Concepts and Transformational Learning. Rotterdam: Sense Publishers 2010. p. 147- 164.

Quinnell, R., Thompson, R., \& Lebard, R. (2013). It's not maths; it's science: exploring thinking dispositions, learning thresholds and mindfulness in science learning. International Journal of Mathematical Education in Science and Technology, 44(6), 808-816. doi:http://dx.doi.org/10.1080/0020739X.2013.800598

Rayner, A., \& Quinnell, R. (2016). Coloured by hand. MUSE, 15(22-23). Retrieved 1 April, 2019: http://sydney.edu.au/museums/publications/muse/muse-nov2016.pdf

Sowden, H. (curator). (2018). Haswell Museum data. Retrieved 1 April, 2019: https://collections.ala.org.au/public/show/co275

Taylor, P.C. (2018). Enriching STEM with the arts to better prepare 21st century citizens. AIP Conference Proceedings, 1923(1), 89-93. doi:10.1063/1.5019491

Trowler, P. R., \& Cooper, A. (2002). Teaching and learning regimes: implicit theories and recurrent practices in the enhancement of teaching and learning through educational development programmes. Higher Education Research and Development, 21(3), 221-240. 